УДК 519.9

\title{
СРАВНЕНИЕ МЕТОДОВ ПОЛУЧЕНИЯ ФАЗОВЫХ ФОТООТВЕТНЫХ ИЗОБРАЖЕНИЙ ПРИ СКАНИРОВАНИИ ПОЛУПРОВОДНИКОВЫХ ГЕТЕРОСТРУКТУР ПЕРПЕНДИКУЛЯРНО ПЛОСКОСТИ $p-n$ ПЕРЕХОДА
}

\author{
КОЛЕНОВ С. А. \\ Киевский наииональный университет имени Тараса Шевченко, \\ Украина, Киев, 01601, ул. Владимирская, 64/13
}

\begin{abstract}
Аннотация. Проведен сравнительный анализ фазовых методов исследования фотоэлектрического отклика на примере сканирования полупроводниковой структуры лазерного диода на основе AlGalnP в направлении, перпендикулярном плоскости $p-n$ перехода. Экспериментально выявлено и теоретически обосновано различие в результатах, получаемых с помощью фазового и дифференциально-фазового методов исследования. Показано, что дифференциально-фазовый метод исследования позволяет получать дополнительную информацию об оптических свойствах материалов гетероструктуры, которая отсутствует в результатах, получаемых фазовым методом
\end{abstract}

Ключевые слова: дифференциально-фазовый метод; p-n переход; фотоэлектрический отклик; фазовые измерения

\section{ВСТУПЛЕНИЕ}

Развитие полупроводниковой электроники в наше время требует применения быстрых неразрушающих методов исследования и контроля полупроводниковых структур. Известно множество методов, основанных на использовании ряда оптических, электрических и рентгеновских измерений [1]. Особое место среди них занимает метод сканирующей лазерной микроскопии LBIC (Light Beam Induced Current) [2], основанный на появлении фотоЭДС при локальной засветке пространственно неоднородного слоя полупроводникового материала.

Источником информации в этом методе является амплитуда и фаза фототока, который наводится в приповерхностном слое исследуемой полупроводниковой структуры при ее сканировании сфокусированным лазерным пуч- ком (амплитудно-модулированным в случае измерения фазы). В связи с этим, в методе LBIC различают амплитудный [2] и фазовый [3] режимы измерения. Амплитудный режим в основном используется для контроля качества изготовления солнечных элементов [4]. Однако, как и другие амплитудные методики, он имеет существенный недостаток - сгенерированные светом возле поверхности носители заряда при распространении в объеме полупроводника «расплываются», что приводит к уменьшению общей амплитуды тока и соответственно к уменьшению контрастности полученных изображений.

С другой стороны, как показано в [3], использование в качестве источника информации фазы фототока дает возможность получать ряд дополнительных сведений о свойствах полупроводника, связанных с временем жизни 